\title{
¿Debates del estado de la nación control parlamentario o puesta en escena para medios de comunicación?
}

\author{
Francisco QUINTERo GonZÁLEZ \\ Universidad de Málaga \\ Franciscoquinterog@hotmail.com
}

\section{Resumen:}

Los debates del estado de la nación en las Cortes Generales como herramienta de control político y su repercusión en los medios de comunicación. El mensaje político y la lectura que hacen de él la prensa escrita.

Palabras clave: Debates; estado; nación; control; parlamento; comunicación.

Debates of the nation state, parliamentary control or staged for the media?

\begin{abstract}
:
The debates on the State of the nation (Spain) as a parliamentary control. The repercussion and the high visibility in the news media.

Key Words: Debates, state, nation, control, parliament, news media.

Referencia normalizada:

Quintero González, F. (2014): ¿Debates del estado de la nación control parlamentario o puesta en escena para medios de comunicación?. Historia y Comunicación Social. Vol. 19. Núm. Especial Febrero. Págs. 793-804.
\end{abstract}

Sumario: 1. Introducción. 2. Metodología. 3. Marco temporal y características. 3.1. Control parlamentario. 4. Conclusiones. 5. Referencias bibliográficas.

\section{Introducción}

En 1982 Felipe González alcanzó el poder con una holgada mayoría absoluta. Un año más tarde se puso en marcha la iniciativa de un debate sobre la situación general del Estado. El Presidente del Gobierno, Felipe González, recogía en su primera intervención en el primer debate sobre el estado general de la Nación al hilo de esta experiencia política novedosa lo siguiente': "Me complace comparecer ante la Cámara,

1 En el B.O.C.G. de 20 de Septiembre de 1983 en su página 2625 
por iniciativa del Gobierno, antes de cumplirse diez meses de mandato del mismo. Y me complace hacerlo para abrir un debate que significa también una experiencia nueva. Un debate sobre la situación general de España. [...] Es difícil definir el carácter de este debate por constituir una experiencia que no se había producido, que tengo la esperanza de que sea fructífera y también de que se repita en años ulteriores".

El gobierno adoptó esta decisión de manera voluntaria e instauró el debate sobre el estado de la nación. Desde entonces sirve para hacer balance de la labor del Ejecutivo durante el año. Aunque la nomenclatura que se utiliza "estado de la nación" hace remitir, más como un simbolismo que como una realidad, a los debates de inicio del año político propios de los regímenes presidencialistas ${ }^{2}$. Mostrándose como casos muy distintos al que nos ocupa.

Desde entonces hasta la actualidad se han celebrado veintidós debates del estado de la nación, como media tres por legislatura. Se trata de una práctica parlamentaria continuada que, sin embargo, no tiene regulación específica para su desarrollo. En claro contraste a la celebración de similares actos en el Senado, parlamentos autonómicos o debates del estado de la ciudad que sí están regularizados. Otra singularidad destacada es que a lo largo de los últimos 28 años los tres presidentes del gobierno, los distintos ejecutivos, con sus respectivas características de mayorías relativas o absolutas, lo han conservado como uso. A tenor de su regularidad y la carta de normalidad atribuida a la realización de los debates del estado de la nación las preguntas que pudieran dar respuesta a los problemas de investigación serían las siguientes: ¿Cuáles son las funciones? ¿Cuáles son sus orígenes? ¿Cuál es la estructura de los debates? ¿Cómo es posible que carezca de regulación expresa esta práctica parlamentaria que hipotéticamente puede haber adquirido el rango de costumbre parlamentaria? ¿Se ha pretendido dejar abierta la posibilidad de su celebración siempre en manos del gobierno de turno ante la ausencia de regulación?

\section{Metodología.}

Son abundantes los estudios sobre el Parlamento, y en especial, sobre el parlamentarismo español. No obstante la ingente bibliografía al respecto no se ha detenido en el análisis sobre los debates del estado de la nación. Reconocer esta ausencia justifica el objeto o iniciativa de esta investigación en los citados debates, una actividad parlamentaria reiterada en el tiempo y que carece de regulación jurídica.

2 El más conocido es el discurso sobre el "Estado de la Unión" que pronuncia el Presidente de Estados Unidos a comienzos de año que se recoge en el artículo segundo en su sección tercera de la Constitución norteamericana. Existen otros ejemplos de esta naturaleza menos conocidos y recogidos en los textos legales de referencia como la Constitución de la República de Ghana, en la Constitución de la República Democrática del Congo o en la Constitución de la República de Benin entre otras. Así como los usos de los mismos recogidos por el Parlamento de Sudáfrica para la realización del Debate del Estado del País, en el Reglamento de la Asamblea de la República en Portugal o en el Reglamento interno de la Asamblea de Diputados del Gran Ducado de Luxemburgo. 
Para tratar de responder a cuáles son sus funciones es recomendable destacar que los debates del estado de la nación nunca se han regulado como control parlamentario y, por otra parte, que las sucesivas Memorias del Congreso lo enmarcan dentro de la función de orientación. Por lo que otra hipótesis a tener en cuenta sería considerar los debates como un instrumento mixto de control o de orientación.

Existen diferentes teorías al respecto por lo que hace difícil el trabajo ante esa escasa regulación y las diversas teorías políticas que no se decantan ante el instrumento de control o la figura mixta. Para aproximarnos a lo que podría definirse como una laguna jurídica o política en la práctica parlamentaria. El marco temporal de análisis de los debates del estado de la nación serán los celebrados en la VIII Legislatura, que comprende tres debates. Estos nos servirán como referencia para analizar, desgranar y detallar los contenidos de los mismos en un ámbito micro. Ya que sería pretencioso la observación de los veintidós debates del estado de la nación en una investigación de estas características. Además, porque, al comprender una legislatura completa, la VIII, puede ofrecer una información de conjunto amplia y suficiente del contenido de los debates.

El tipo de investigación que se va a realizar se puede clasificar como "analítica-conceptual" porque su objetivo es una "elaboración conceptual" para explicar ¿qué es? También se puede incluir como tipo de investigación "empírico-descriptiva" ya que entre los objetivos de la misma está "la exploración y descripción de la inferencia descriptiva" para dar respuesta a cuestiones como: ¿Cómo sucede? ¿Cómo es? ${ }^{3}$ Una de las hipótesis que se pretende desarrollar sería verificar si los debates del estado de la nación se pudieran asimilar a alguna de las herramientas de control que posee el parlamento y relacionar, si se pudiera, sus características entre sí. Sin embargo, cabe destacar, de antemano, que la Memoria ${ }^{4}$ de la VIII Legislatura, al igual que en anteriores publicadas por el Congreso de los Diputados, ubica en la consideración del debate como una iniciativa clasificada como de "función de orientación". Lo hace a tenor de las características que a lo largo del tiempo ha adquirido el mismo en su desarrollo. Puesto que nunca ha sido definido por la Mesa del Congreso como una iniciativa de control, ya que el Reglamento de la Cámara o cualquier otra disposición normativa así lo hace.

Los debates del estado de la nación podrían definirse como una costumbre parlamentaria que analiza un hecho concreto: el grado de ejecución de las propuestas presentadas en el programa del Gobierno de la Nación. Su función se asemejaría al control parlamentario por su papel fiscalizador al Gobierno, exposición de sus iniciativas y tribuna del balance que hace el Presidente del Gobierno de la situación política, social y macroeconómica del Estado. El Debate del Estado de la Nación no lo reconoce la Constitución, ni los reglamentos parlamentarios, se consolida por la

3 Anduiza Eva; Crespo Ismael y Méndez Lago Mónica. Cuadernos Metodológicos No 28. Metodología de la Ciencia Política. CIS. Madrid.

4 Ripollés M.R.; Álvaro A. y Gonzalo M.A., (2011) Memoria de la VIII Legislatura (2004-2008). Madrid. Congreso de los Diputados, Gabinete de Publicaciones. 
práctica, se desarrolla en el Congreso de los Diputados y es la explicación por parte del Presidente de la política general llevada a término por su gobierno. Sería un uso parlamentario que se inició a mediados de los años ochenta del siglo pasado y se ha convertido por su solemnidad, formato y la amplitud de los temas que trata en uno de los debates más importantes de cada año. Este boato se lo da el Presidente del Gobierno, ya que hace balance de su gestión de gobierno y presenta nuevos anuncios sobre decisiones políticas del ejercicio anual. Del mismo modo, abunda en el sentido de la solemnidad la participación de todos los portavoces de los distintos Grupos Parlamentarios con representación en la Cámara baja, esmerándose en la preparación de dichas intervenciones, en el diseño de su estrategia parlamentaria (alianzas, acuerdos de enmiendas o sentido de la votación), discurso de contestación y réplica de los distintos protagonistas del debate del estado de la nación en cada cita.

El formato contribuye a que despierte en los distintos medios de comunicación un especial interés ${ }^{5}$ y por ende en la sociedad española, dado el calado de los asuntos tratados. Empíricamente se ha podido observar que la visibilidad, ya alta desde el principio, de las noticias aumenta, predomina el debate de temas no técnicos, se distingue la repercusión del mismo entre gobiernos con mayoría absoluta o aumento del pluralismo, así como otras características. La repercusión y la alta visibilidad se explican por la importancia que da la sociedad española al Congreso de los Diputados. Así en el estudio número 2778 del Centro de Investigaciones Sociológicas de Noviembre de 2008 se recoge que para el $79,4 \%$ de los encuestados opina el Congreso de los Diputados es muy o bastante importante. Del mismo modo, en relación con una de las hipótesis de este trabajo, tan sólo el 16,8\% cree que entre las funciones del Congreso se encuentra las de controlar la acción del gobierno. El gobierno determina el momento a celebrarse, lo hace remitiendo al Congreso una Comunicación ${ }^{6}$ : "El Gobierno, con unos diez días de antelación al momento en que desea que se produzca el debate, remite una Comunicación al Congreso, en la que formula un diagnóstico de la situación económica, política y social del país, presenta un balance de su propia gestión en el año transcurrido desde el debate anterior y fija los objetivos que se propone alcanzar en el período siguiente. La comunicación suele consistir en unos pocos folios y es muy genérica, para permitir así mayor libertad al Gobierno en su exposición oral ante la Cámara, y poco aclaratoria para los Grupos de la oposición sobre cuáles son las intenciones prioritarias de la mayoría." Los distintos gobiernos establecen el balance y el resumen que les conviene con gran flexibilidad, lo comparan con el año anterior o en cualquier otro periodo que les favorezca. De manera muy llamativa los discursos son autocomplacientes e intentan ocultar todo incumplimiento de lo asumido en el debate anterior. Las mencionadas "comunicacio-

5 En las distintas fechas de celebración se retransmite en directo por la cadena pública estatal (RTVE) y la prensa escrita hace suplementos informativos especiales. En la actualidad, todos los medios de comunicación en sus soportes digitales hacen un seguimiento pormenorizado e inmediato vía redes sociales de lo que en los debates del estado de la nación se discute.

6 Guerrero Salom, Enrique. El Parlamento qué es, cómo funciona, qué hace. Editorial Síntesis. Madrid. Pág. 224. 
nes al gobierno" se recogen en el Título XI, Capítulo I del Reglamento del Congreso de los Diputados en sus artículos ${ }^{7} 196$ y 197. Después de intervenir el Presidente lo hacen los portavoces de los grupos parlamentarios comenzando por el grupo mayoritario de la oposición hasta llegar al grupo mixto o minoritario de la oposición, si bien la última de las intervenciones de los grupos parlamentarios la hace el portavoz del grupo que sostiene al gobierno, en este caso al tratarse de la VIII Legislatura, el socialista.

Para más de las tres cuartas partes de los ciudadanos consideran al parlamento muy o bastante importante para el buen funcionamiento de la democracia, y apenas llegan al $10 \%$ los que creen que es poco o nada importante en este sentido (el barómetro de opinión del Centro de Investigaciones Sociológicas de Septiembre de 2003, mostraba que el $76 \%$ de los españoles consideraban muy o bastante importante el Congreso de los Diputados para el funcionamiento de la democracia, mientras que el $8 \%$ lo consideraba poco o nada importante; los datos para el Senado eran del 65,4\% y del 15,4\% respectivamente ). "En cierto sentido se produce una identificación entre Gobierno y Parlamento, los españoles consideran que el papel fundamental del Parlamento es representar la nación pero también la de controlar al Gobierno [...] y lo valoran mejor, lo que es un indicador de que se sienten globalmente más representados por éste que por el Gobierno, al que identifican con una sólo opción política"8. Esta cita nos da pie para explicar que el interés de este trabajo es que se trata de un estudio de caso sobre el impacto y relevancia en la investigación de los debates del estado de la nación. Se centra en el Parlamento, en el discurso político de los principales líderes en el mismo y el objeto final de los debates del estado de la nación.

En el debate del estado de la nación el gobierno busca fortalecer sus principales acciones. Para ello acude, voluntariamente, a exponer los planes del ejecutivo. Por su parte, la oposición ejerce el papel de control propio de las funciones que tiene atribuidas. Esto se produce porque si bien no es una iniciativa de control como tal, sí parece tener unas funciones semejantes. Especialmente, cuando el Gobierno llega a la cita y pone sobre la mesa sus hechos y las acciones futuras, siendo objeto de las críticas propias de los distintos grupos de la oposición, y obteniendo la aprobación del grupo o los grupos que sostienen al Gobierno. En este caso al margen de las funciones de representatividad, legislativas y específicas de control al Gobierno que tiene el Parlamento, dada la voluntariedad del Ejecutivo a prestarse al debate del

7 Es a través de estos artículos con los que el primer Gobierno de Felipe González se dirige a la Cámara en 1983 para solicitar el primero de los debates celebrados. En él se recogía en su preámbulo lo siguiente: "Tengo la honra de enviar a V.E., en nombre del Gobierno, a los efectos de los dispuesto en el artículo 196 y 197 del Reglamento del Congreso de los Diputados, la adjunta comunicación para su debate en el Pleno de la Cámara". Remitida desde la Secretaría de Estado para las Relaciones con las Cortes y la Coordinación Legislativa al Presidente del Congreso de los Diputados. Con número de registro de entrada: 4260 de 16 de Septiembre de 1983.

8 Guerrero Salom, Enrique. El Parlamento qué es, cómo funciona, qué hace. Editorial Síntesis. Madrid Pág. 63. 
estado de la nación, éste y sus connotaciones de control podrían perderse si futuros gobiernos decidieran no celebrarlo.

\section{Marco temporal y características.}

En el análisis de este trabajo, como se hizo referencia anteriormente, nos vamos a ocupar de los debates del estado de la nación de la VIII Legislatura que se produjeron el 11 de Mayo de 2005, el 30 de Mayo de 2006 y el 3 de Julio de 2007, en todos los casos se celebraron durante varios días. Como marca la tradición no se han llevado a cabo en aquellos años en que o bien se han producido unas elecciones generales o bien éstas se celebraron en los últimos meses del año anterior y, por lo tanto, en el año entrante no se pudieron poner en marcha acciones de gobierno claras para que las expusiera el Presidente del Gobierno.

El contexto temporal actual y las características especiales de inmediatez e interacción propias del momento requieren que las demandas sociales tengan una rápida respuesta política ${ }^{9}$. Hasta hace, relativamente, poco tiempo las cuestiones políticas estaban más asentadas en una parsimoniosa actitud burocrática asimilada por la mayoría. Se asumía la representatividad de la ciudadanía en los parlamentos y se aceptaba el control lento, laxo y periódico de las elecciones generales. De forma evidente los tiempos y las circunstancias han cambiado. La rigurosa actualidad requiere raudas respuestas y fieles sistemas de control que contesten de manera fiable a los interrogantes de la sociedad y cualquiera de sus creadores de opinión. Por lo tanto la demanda de control sobre las decisiones públicas no son más que una coherencia propia de sociedades más avanzadas y que buscan profundizar en los mecanismos democráticos de control a las acciones de los gobiernos. En "ese circuito $^{10}$ de control" y fiscalización de la sociedad civil se ubica en este análisis los debates del estado de la nación. ¿Por qué carecen de regulación los debates del estado de la nación que hipotéticamente han adquirido rango de costumbre parlamentaria? Podríamos definirlos como un uso parlamentario cuya finalidad más cercana se sitúa en el examen de apoyos del Gobierno, de cumplimiento del programa electoral o del grado de ejecución de las propuestas lanzadas en el debate de toma de posesión del Presidente del Gobierno. El debate del estado de la nación encontraría plasmación en el denominado "control parlamentario" (Art.66.2. C.E.). La doctrina más extendida

9 La desafección política mundial se muestra con asiduidad en los movimientos sociales de protesta. Una desafección que no es sólo actual, sino que también se han dado en otros tiempos anteriores, ni tampoco sólo se suscribe a movimientos sociales reivindicativos sino que se da en amplios sectores de la sociedad. En el caso español según los estudios demoscópicos "la clase política y a los partidos políticos" se les sitúa como "tercer principal problema que existe actualmente en España" (Estudio n ${ }^{\circ}$ 2888. Barómetro del CIS de Mayo de 2011)

10 Porras Nadales, A. (1997). El debate sobre la crisis de la representación politica. Madrid. Tecnos. 
es que la función de control del Parlamento ha sustituido en importancia a la legislativa por la relevancia ${ }^{11}$ de los asuntos tratados.

\subsection{Control parlamentario.}

El control parlamentario lo ejerce el Parlamento sobre el Gobierno por múltiples vías. Esta función aparece atribuida a las Cortes Generales por el artículo 66.2 de la Constitución Española. El control parlamentario facilita a la Cámara detectar y aislar los aspectos programáticos incumplidos por el Ejecutivo. De esta manera se traslada a la opinión pública las carencias observadas tanto en el funcionamiento del gobierno, de las administraciones públicas o de los servicios públicos por él dirigidos. Los mecanismos dispuestos para ello se recogen en su mayoría en el Reglamento del Congreso de los Diputados, al margen de las deducciones de responsabilidad política derivadas de incumplimientos programáticos o de pérdidas de votaciones en sede parlamentaria por falta de apoyos suficientes.

A tenor de las características citadas, el debate del estado de la nación las tiene en su haber para poder definirlo como una herramienta más de control parlamentario.

Se podría afirmar que estos debates se convierten en "debates control". La oposición podría presentar, de igual manera, las propuestas que estime necesarias (dentro del número acordado en la Mesa del Congreso para la celebración de este debate) y tantas críticas políticas como el momento ofrezca. Pero, al mismo tiempo, mayorías alternativas y el propio gobierno puede defender sus posiciones y sus propuestas políticas a través de nuevos anuncios o exposición de las razones por las decisiones tomadas.

En el debate del estado de la nación al margen de su solemnidad, la agilidad y el carácter de control político al Gobierno hay un asunto que queda poco consolidado en su práctica. A pesar de ser considerado un uso parlamentario en la actualidad, ante la falta de regulación de la convocatoria, es el gobierno quién determina cuándo se celebra este debate. Dada la importancia y el valor parlamentario del que goza y la destacada labor de control que ejerce sobre el poder ejecutivo no debería quedar al arbitrio del gobierno la remisión de esa Comunicación al Parlamento. El Reglamento de la Cámara podría ser un lugar perfecto para recoger la estructura del debate y otros datos como periodicidad y fecha en atención a la importancia política del mismo. Evitando de esta forma la posibilidad de que futuros gobiernos decidieran relegarlo.

Este trabajo ha querido establecer una hipotética relación sobre el carácter de control parlamentario del debate del estado de la nación. Con el objetivo de buscar el establecimiento de un reglamento y ordenación de un nuevo modelo de control al gobierno que pudiera ser el debate del estado de la nación. De esta manera una de las

11 García Morillo, J. "El Parlamento en la Era Global”. Cuadernos de Derecho Público. N. ${ }^{\circ} 11997$, págs. 81 y ss. Molas, I. Pitarch, I. Las Cortes Generales en el Sistema Parlamentario de Gobierno, opus cit. págs 19 y ss. Martínez Elipe, L. Tratado de Derecho Parlamentario. Fiscalización Política del Gobierno. VI. Aranzadi. Madrid 200. págs 197 y ss. 
conclusiones a la que se puede llegar con este análisis, es situar al debate del estado de la nación como otro acto político más de control, al igual que el caso de convalidaciones de Decretos Leyes, aprobación de Proyectos de Ley, entre otros en la línea de control al Gobierno, fundamentado en el ordenamiento jurídico.

La búsqueda de este contexto jurídico nada tiene que ver con la confusión entre control jurídico o político que diversos teóricos y politólogos debaten con intensidad. El debate del estado de la nación escapa del control jurídico por su no regulación, por lo que este estudio propone como una de sus conclusiones principales la normativización sólo con carácter político. Sin incluirse entre los instrumentos de control jurídico (interpelaciones o mociones de consecuencia) sólo con carácter político.

\section{Conclusiones.}

El parlamentarismo es una de las disciplinas más estudiadas y analizadas en Ciencia Política. Una de sus manifestaciones más reconocibles entre las realizadas en el seno del Parlamento español son los debates del estado de la nación.

Destaca entre otras acciones políticas del Parlamento no sólo por la notoriedad que adquiere, demostrada en este trabajo, sino también por la ausencia de unos patrones regularizados para su celebración legislatura tras legislatura. El Reglamento del Congreso de los Diputados, otras normas interpretativas y supletorias vigentes del mencionado reglamento y leyes que regulan distintas materias ( Defensa, Consejo General del Poder Judicial entre otras) recogen los procedimientos y las pautas a seguir para la toma en consideración por la Cámara de comparecencias, interpelaciones o cualquier otra herramienta de control que en plena facultad de las competencias que le atribuye el ordenamiento constitucional son propias del Congreso de los Diputados. Sin embargo, los debates del estado de la nación están al arbitrio de la voluntariedad del Gobierno de turno de comparecer a petición propia para la celebración de un "debate de política general en torno al estado de la Nación" y la distribución del mismo a las decisiones que tomen la Junta de Portavoces y la Mesa del Congreso. Frente a esta desregulación se ha contrapuesto la que existe en el Senado, los reglamentos de los parlamentos autonómicos y en los reglamentos orgánicos de los plenos de las grandes ciudades españolas.

A pesar de haberse celebrado hasta el momento veintidós debates del estado de la nación y entenderse a tenor de las conclusiones que emanan de este estudio que se está ante un uso parlamentario con suficientes raíces políticas como para que se garanticen futuras citas con los debates del estado de la nación, nada impediría que futuros gobiernos decidieran no enviar dicha comunicación al Parlamento para la celebración del debate sobre política general. Porque no existe ninguna norma de mayor o menor rango que recoja dicho cumplimiento, su desarrollo o tramitación. El gobierno se limita a utilizar la puerta que le deja abierta los artículos 196 y 197 del Reglamento de las Cortes Generales "De las comunicaciones del Gobierno", y 
así, continuar con la costumbre parlamentaria utilizada desde sus comienzos por el primer gobierno socialista del Presidente, Felipe González, y propiciar su celebración en los años que se realiza. También ya, bajo el paraguas de la costumbre nunca se ha llevado a cabo en años en que o bien se han producido unas elecciones generales o bien éstas se celebraron en los últimos meses del año anterior.

En este trabajo también ha quedado reflejado con nitidez que los debates del estado de la nación son una herramienta de control más porque se inspecciona, comprueba y verifican los cumplimientos del Gobierno. Se ejerce presión sobre el mismo para que dé respuesta a sus compromisos políticos y se ejerce como otro mecanismo de control más en el Parlamento. Si bien, podría definirse como una "fórmula de control mixto" porque no se recoge como tal entre los que reconocen los reglamentos a los que tiene que someterse el Gobierno y, en cualquier caso, al usar la vía de los artículos 196 y 197 del Reglamento del Congreso éste lo hace de forma voluntaria. Otra conclusión aquí recogida sería que la figura política de los debates del estado de la nación no necesita ser regulada jurídicamente para su efectiva realización por parte de los responsables políticos de su celebración.

Los debates del estado de la nación se pueden definir como una "práctica parlamentaria" que el Congreso dota de singularidad en su desarrollo, celebración y posteriores consecuencias de control político sobre el Gobierno. Control que no genera obligaciones más allá de las políticas.

Esta evidente desregulación de los debates del estado de la nación conducen a la aportación final de este estudio: la conclusión constructiva. Los sucesivos intentos de reforma del Reglamento de las Cortes Generales iniciados en pasadas legislaturas no han intentado en ninguna ocasión regular los mismos. Por lo tanto, dada la importancia de una cita política de estas características este análisis propone la regulación de los debates del estado de la nación para evitar los vaivenes en su celebración: en fechas, tiempos de intervención de portavoces, número de propuestas de resolución admitidas a cada grupo parlamentario, formato de la Comunicación del Gobierno para iniciar el debate y la voluntariedad del Gobierno.

En suma se trataría de evitar que el Gobierno escape al control parlamentario propio del debate del estado de la nación.

\section{Bibliografía}

Aguiar Luque, L. (1997). "La problemática del Control Parlamentario". En M. Ramírez (ed.). El Parlamento a Debate. (Págs.73-107). Madrid. Editorial Trotta. Anduiza Perea; E., Crespo y I. Méndez Lago, M. (1999). Metodología de la Ciencia Política. Madrid. CIS.

Aragón, M. (1995). Constitución y control de poder. Buenos Aires. Argentina. Ediciones Ciudad Argentina. Manuel Aragón. Ediciones Ciudad Argentina. 
Aranda Álvarez, E. (2007) "Transformaciones en los instrumentos de control parlamentario". Teoría y realidad constitucional, 19 : 105-134.

Azaña, M. (1934). En el poder y en la oposición: (1932-1934). Bilbao. Espasa-Calpe. Blondel, J. (1981). El gobierno: estudios comparados. Madrid. Alianza Editorial.

Bustos, R. (2001). La responsabilidad política del Gobierno. Madrid. Colex.

Cruz Villalón, P. (1983) Escritos de Derecho Constitucional, Madrid

Dahl, R.A. (1981). La oposición política en las democracias occidentales. Madrid. Alianza Editorial.

Elías Méndez, Cristina (2005). La moción de censura en España y Alemania. Madrid. Congreso de los Diputados. Departamento de Publicaciones.

Embid Irujo, A. (1992) "El control parlamentario del Gobierno y el principio de la mayoría parlamentaria: algunas reflexiones". Revista de las Cortes Generales, 25: 7-30.

Field, B. N. (2009).”The parliamentary election in Spain, March 2008 “. Electoral studies. -- Vol. 28, n. 1:155-158

García - Escudero Márquez, P. (2003) "La ponencia en el procedimiento legislativo en las Cortes Generales". Revista de las Cortes Generales, 59: 141-215.

García Fernández, J. (1994) "La función de control del Parlamento sobre el Gobierno". Revista de las Cortes Generales., 31: 31-69.

García Herrera, M.A. (1995). Mayoría, minoría y control parlamentario. VI Jornadas de Derecho Parlamentario. Madrid. Congreso de los Diputados. Departamento de Publicaciones.

(1995) Problemas actuales del control parlamentario: enero 1995. VI Jornadas de Derecho Parlamentario. Madrid. Congreso de los Diputados, Departamento de Publicaciones.

García Morillo, J. "El Parlamento en la Era Global”. Cuadernos de Derecho Público. N. ${ }^{\circ} 11997$, págs. 81 y ss.

Grupo Parlamentario Popular del Congreso. (1983). Doscientos días de oposición parlamentaria: diciembre 1982-julio 1983. Madrid. Editorial: Grupo Parlamentario Popular del Congreso.

Guerrero Salom, E. (2004). El parlamento: qué es, cómo funciona, qué hace. Madrid: Síntesis.

(2000) La actividad del Congreso: una evaluación. El Congreso de los Diputados en España: funciones y rendimiento. Madrid. Tecnos.

(1999) La actualidad del control parlamentario y algunos de sus problemas más relevantes. Madrid: Tecnos. (págs. 449-471)

Holgado González, M. (2008). El programa de gobierno y sus sistemas de control, Tirant lo Blanch.

Key G.; Keohane, R. y Verba S. (2000) El diseño de la investigación social. La inferencia cientifica en los estudios cualitativos. Madrid. Alianza Editorial.

Marsh, D. y Stoker G. (1997). Teoría y Métodos de la Ciencia Política. Madrid. Alianza Editorial.

Martínez, A. (2000). El Congreso de los Diputados en España: funciones y rendimiento. Madrid. Tecnos. 
Martínez Elipe, L. (2000) Tratado de Derecho Parlamentario. Fiscalización Política del Gobierno. VI. Aranzadi. Madrid. págs 197 y ss

Molas, I. Pitarch. Las Cortes Generales en el Sistema Parlamentario de Gobierno, opus cit. págs 19 y ss.

Peñaranda Ramos, J.L. (1985) Debate sobre la comunicación del Gobierno acerca del estado de la nación. Madrid. Congreso de los Diputados, Gabinete de Publicaciones.

Porras Nadales, A. (1997). El debate sobre la crisis de la representación política. Madrid. Tecnos.

Requejo, J. L. (2004). "Las relaciones entre el gobierno y las Cortes Generales", REDC, 70.

Ripollés M.R.; Álvaro A. y Gonzalo M.A., (2011) Memoria de la VIII Legislatura (2004-2008). Madrid. Congreso de los Diputados, Gabinete de Publicaciones

Santamaría Ossorio, J. (1997). Democracia parlamentaria y sistemas de partidos. Madrid. Trotta ( págs. 173-180)

(1994). "El papel del Parlamento durante la consolidación de la democracia y después". Revista de estudios políticos, 84:9-25

Santaolalla López, F. (1982) El Parlamento y sus instrumentos de información. Madrid. Edersa.

Serrano Jaúregui, N. (1991). El acto parlamentario. Vitoria-Gasteiz: Eusko Legebiltzarra $=$ Parlamento Vasco. (págs. 453-477)

Sodaro, M. (2004). "La Ciencia Política Empírica (I) . Métodos y técnicas de investigación" en M. Sodaro, Política y Ciencia Política. Una Introducción. Madrid. McGraw - Hill.

Torres del Moral, A. (1981). "Los grupos parlamentarios". Revista de derecho político, 9: 21-66.

Virgalia Foruria, E., La moción de censura en la Constitución de 1978. Madrid. CEPC.

Diarios de Sesiones de las Cortes Generales.

http://epp.eurostat.ec.europa.eu/portal/page/portal/eurostat/home

Revista Española de Ciencia Política, 10: 9-51 (disponible en http://www.aecpa.es/ archivos/publicaciones/recp/10/textos/01.pdf ) [10-02-2013]

www.congreso.es [09-12-2012]

www.senado.es [09-12-2012]

www.abc.es [13-03-2013]

www.elpais.es [12-02-2013]

http://www.elpais.com/comunes/2007/debate-estado-nacion/historial-debate-estado-nacion.html [13-03-2013]

http://hemeroteca.abc.es [13-03-2013] 


\section{El autor}

Francisco Quintero González. Doctorando en la Universidad de Málaga en el programa de Doctorado "Periodismo nuevos escenarios". En la actualidad Coordinador del Grupo Municipal socialista en el Ayuntamiento de Málaga, España. Con anterioridad he desempeñado tareas de asesoramiento político en la Diputación de Málaga y en las Cortes Generales españolas. Previas a estas tareas realicé colaboraciones en distintos medios de comunicación escritos y audiovisuales. Máster Oficial en Democracia y Política por la Facultad de Ciencias Políticas de la UNED. 